\title{
The use of infrared thermography and accelerometers for remote monitoring of dairy cow health and welfare
}

\author{
M. Stewart, ${ }^{* 1}$ M. T. Wilson, ${ }^{*}$ A. L. Schaefer, $†$ F. Huddart, $\ddagger$ and M. A. Sutherland $\ddagger$ \\ *InterAg, Ruakura Research Centre, 10 Bisley Rd., Hamilton 3214, New Zealand \\ †Animal Inframetrics, Box 5451, Lacombe, AB, T4L 1X2, Canada \\ $\ddagger$ AgResearch Ltd., Private Bag 3123, Hamilton 3240, New Zealand
}

\section{ABSTRACT}

Increasing reliance on automated systems on-farm has led to a need for remote monitoring of health and welfare. We aimed to validate 2 methods that could be integrated into automated systems currently in use: infrared thermography (IRT) to measure respiration rate (RR), and accelerometers to measure the flinch, step, kick (FSK) response and assessing stress and discomfort. We monitored 22 multiparous, nonlactating, Friesian and Friesian $\times$ Jersey cows (average 5.1 yr of age) during a baseline period (2 min), a restraint in a crush $(2 \mathrm{~min})$, and then a recovery period after exposure to a startle $(2 \mathrm{~min})$. We measured RR with continuous IRT imaging of airflow through the nostrils and by counting flank movements from video and live recordings. We recorded heart rate (HR) and HR variability using HR monitors, and we recorded FSK from continuous video analysis of leg movements and indirectly using accelerometers attached to both hind legs. The FSK response was scored between 1 and 4 based on the height and direction of each leg movement. We observed no change in $R R, H R$ variability, or FSK in response to the startle; however, HR increased briefly by $10 \mathrm{bpm}$. Bland-Altman plots indicated good agreement between the different methods of measuring $\mathrm{RR}$, with average differences of $-0.01 \pm 0.87,0.83 \pm$ 0.57 , and $0.37 \pm 1.02$ breaths $/ \mathrm{min}$ for video versus live, IRT versus live and IRT versus video, respectively. Acceleration was also highly correlated with FSK scores of $\leq 3\left(\mathrm{R}^{2}=0.96\right)$ and $\leq 2\left(\mathrm{R}^{2}=0.89\right)$ and moderately correlated with FSK scores of $1\left(\mathrm{R}^{2}=0.66\right)$ over the 4-min sampling period. The results show that accelerometers can provide an indirect measure of the FSK response, and IRT can be used reliably to measure RR. With further development, both technologies could be

\footnotetext{
Received September 26, 2016.

Accepted December 18, 2016.

${ }^{1}$ Corresponding author: mairi.stewart@interag.co.nz
}

integrated into existing systems for remote monitoring of dairy cows' health and welfare on-farm.

Key words: dairy cow, respiration rate, accelerometers, heart rate, infrared thermography

\section{INTRODUCTION}

In recent years in the dairy industry, reliance on automated in-shed systems (such as automatic cup removers and drafting gates) to reduce labor has been increasing. The wide use of radiofrequency identification systems has opened up opportunities for the remote monitoring of individual cows. Remote monitoring systems allow noninvasive, non-contact data collection that can be streamed in real time or downloaded to provide information about an animal's biological state (e.g., activity, behavior, physiology). For example, rumination and activity monitors (using accelerometer or pedometer technology) attached to the leg or neck collar have become common for detecting estrus in dairy cows (Roelofs and van Erp-van der Kooij, 2015). Due to this shift toward automation and the declining number of experienced stock people entering the industry, along with increasing herd sizes (DairyNZ, 2015; Lyons et al., 2016), automated remote monitoring of health and welfare on-farm is needed. For example, the size of the average dairy herd in New Zealand (419 cows) has tripled in the last 30 years, and herds of 2,000 to 3,000 cows are not uncommon (DairyNZ, 2015). Increasing herd size leads to less individual monitoring of cows.

Respiration rate $(\mathbf{R R})$ can be affected by stress and heat exposure (Schütz et al., 2014), pain (Stewart et al., 2013), and disease (Gershwin et al., 2015); therefore, changes in RR can be a useful indicator of these physiological states. Respiration is the physiological act of breathing, or more specifically, the act of taking in oxygen, which is conveyed to the tissues and cells in the body, followed by the release of carbon dioxide. One method for measuring RR in dairy cows is to record the time it takes for a cow to take 10 breaths: the number of flank movements as the animal inhales and 
exhales. Although this method has been used reliably, for example to assess heat stress in cows (Schütz et al., 2014), it is very labor-intensive, and flank movements can be difficult to observe in colder climates or with shallow breathing (e.g., during disease onset). This method also requires that observers be near the animal, which could cause a stress response in some animals and affect the validity of the recordings. Some remote devices have been developed to measure $\mathrm{RR}$ in cattle. Typically, they involve sensors that measure chest-wall movements (e.g., strain gauges or pressure transducers). For example, Eigenberg et al. (2000) developed a RR monitoring system for cattle that used a thoracic belt to keep the transducer in place. Although remote monitoring is possible, this equipment is cumbersome and not practical for long-term recording. Similar to heart rate (HR) monitoring systems, this approach is impractical and susceptible to displacement and damage. Also, having such bulky equipment fitted to the animal could cause changes in normal behavioral patterns and increase stress, affecting the accuracy of the results. Pastell et al. (2006) developed a laser-based contactless method for measuring RR in an automatic milking system. However, a major limitation was that it could not be used on black cows, because the laser was absorbed by their dark hair. To be practical on-farm, a RR monitoring system must be contactless, capable of real-time monitoring, and account for variations in animal characteristics.

Infrared thermography (IRT) measures radiated heat, and studies in cattle have shown that this technology can detect thermal changes before clinical signs occur in the onset of bovine viral diarrhea (Schaefer et al., 2004), bovine respiratory disease (Schaefer et al., 2012), and neonatal calf diarrhea (Lowe et al., 2016). Other studies have investigated IRT as a noninvasive tool for detecting mastitis (Polat et al., 2010), lameness (Alsaaod and Büscher, 2012), stress (Stewart et al., 2008), pain (Stewart et al., 2009), and estrus (Talukder et al., 2014) in cattle. The study by Schaefer et al. (2012) was the first demonstration of an automated IRT system, whereby IRT images were captured every time the animal visited a water trough to drink. The diseases mentioned above are all associated with localized inflammatory response (e.g., respiratory tract, intestines), and during their onset, animals use other mechanisms for heat loss (e.g., radiated heat) to maintain a normal core body temperature. By combining RR monitoring with IRT, it could be possible to detect other conditions that may not cause an inflammatory response, such as metabolic diseases (e.g., ketosis, rumen acidosis, bloat) or stress and discomfort. Human studies have investigated IRT for measuring RR (Ab- bas et al., 2011; Lewis et al., 2011). Lewis et al. (2011) developed an algorithm that could accurately extract $\mathrm{RR}$ and relative tidal volume in 25 adult participants. Using continuous IRT video recording of the nostrils, changes in temperature during the breathing cycle can be detected: inhaling brings in external air and cools the nostrils, whereas exhaling expels air from the body core and warms the nostrils. This technology could be developed for non-contact RR monitoring, without interfering with the animal or fitting equipment.

It is becoming increasingly common for dairy farms to use accelerometers, mainly to assist farmers with estrus detection. One survey of dairy producers reported that $41.3 \%$ of respondents used technologies that measured activity (Borchers and Bewley, 2015). These small devices are attached to the hind leg or neck collar and are likely to be less invasive for the animal and less susceptible to damage or displacement than other devices, such as thoracic belts. It would be beneficial for the farmer if other valuable animal information indicative of pain or discomfort due to lameness, mastitis, or other disease onset could be collected from these devices. One method may be automated monitoring of the flinch, step, kick (FSK) response. The FSK response during milking has been associated with milk production (Willis, 1983; Breuer et al., 2000; Hedlund and Løvlie, 2015); udder health and clinical signs of mastitis (Rousing et al., 2004; Pastell et al., 2006; Medrano-Galarza et al., 2012; Fogsgaard et al., 2015); and lameness (Pastell et al., 2006). However, the method used to measure FSK involves manual scoring of kicks and foot movements, which is labor-intensive and prone to inaccuracies, due to the speed of the movements being recorded and low inter-observer reliability.

The aim of this study was to validate (1) IRT to measure RR, and (2) accelerometers to measure FSK in dairy cows, using a startle as a stress model. Both methods could be developed and integrated into a noninvasive, automated system and replace manual recordings for the on-farm monitoring of animal health and welfare.

\section{MATERIALS AND METHODS}

\section{Animals and Handling Facilities}

The protocol and procedures in this study were approved by the Ruakura Animal Ethics Committee under the New Zealand Animal Welfare Act 1999. This study was conducted in June 2014 (Southern hemisphere winter) in a cattle-handling facility at Ruakura Research Centre, Hamilton, New Zealand. We used 22 pregnant, multiparous, nonlactating Friesian and Frie- 
sian $\times$ Jersey cows, average age $5.1 \pm 1.42$ yr (range 3 to $9 \mathrm{yr}$ ). Cows were managed full-time at pasture as part of normal farm practice and brought into handling yards for the study. The yards (approximately $35 \mathrm{~m}^{2}$ ) had a concrete floor, steel-pipe fences (155 cm high), and a corrugated steel roof. We used a cattle restraint with a head bail (Technipharm Ultimate; Technipharm International Ltd., Rotorua, NZ) to restrain the cows during procedures.

\section{Treatments and Procedures}

The study was conducted over 2 days, $6 \mathrm{~d}$ apart. On d $1(\mathrm{n}=15)$, we measured RR, HR, and FSK response; on $\mathrm{d} 2(\mathrm{n}=7)$, we measured only FSK. To fit equipment (HR monitors and accelerometers, described below) to the cows, the cows were brought into the restraint twice on each experimental day: first for fitting equipment and then for sampling. After equipment fitting, cows were released into an adjacent yard for a 30-min rest period before they were brought in again for sampling.

On d 1, recordings were taken during a 2-min baseline period in a laneway, after the 30-min rest period but before the cow entered the restraint (baseline), and then for $2 \mathrm{~min}$ in a restraint without the head in a head bail (restraint). The cow's head was then restrained in a head bail and the cow was exposed to an experimentally induced startle (startle). This involved a person standing approximately $1.5 \mathrm{~m}$ from the cow's head at a right angle, shouting and rapidly opening and shutting an umbrella for approximately $3 \mathrm{~s}$. The startle was followed by a final 2-min recording period before the equipment was removed and the cow was released back into the yard.

On d 2, cows fitted only with accelerometers were brought straight into the restraint and held with their heads unrestrained for a 2 -min recording period. They were then exposed to the startle, followed by a further 2 -min recording period before the equipment was removed and they were released back into the yard.

\section{$R R$}

On d 1, we measured RR in 15 cows using 3 methods: (1) manual counting of flank movements in real time (live observations); (2) manual counting of flank movements from video recordings; and (3) manual counting of air movement from the nostrils using IRT image recordings.

The live observations consisted of 2 experienced RR observers standing approximately $1 \mathrm{~m}$ from the side of the cow, recording the time it took for a cow to complete 10 breaths, observed from flank movements during baseline and restraint, and following the startle. These recordings were later converted to breaths per min by combining counts from both observers for each 2 -min period. We used the same method to count flank movements (during restraint and following the startle only) from video recordings using a video camera (HDR-CX220E digital HD; Sony, Shanghai, China) mounted approximately $2 \mathrm{~m}$ above the cattle restraint.

We used an IRT camera (ThermaCam S60; FLIR Systems AB, Danderyd, Sweden) to collect continuous image recordings (60 frames/s) of the nose during baseline and restraint, and following the startle. All images were collected by the same camera operator, standing $1.0 \mathrm{~m}$ in front of the cow. Ambient temperature and relative humidity were measured every 30 min using a hand logger (Kestrel 3000; Nielsen-Kellerman, Boothwyn, PA), and we accounted for ambient temperature, relative humidity, distance $(1.0 \mathrm{~m})$, and emissivity (0.98) by entering these details into the camera settings. Figure 1 shows IRT images of a cow inhaling and exhaling. Inhaling brings in the external air and cools the nostrils, whereas exhaling air from the body core warms the nostrils (as illustrated by the lighter colors in the image). To calculate RR, we used image analysis software (ThermaCam Researcher 2.7; FLIR Systems AB) to view the frames from each animal, and 1 observer manually recorded the time it took for each cow to complete 10 breaths, observed from air movements in the nostrils during baseline and restraint, and following the startle.

\section{$H R$ and HR Variability}

On d 1, we recorded continuous HR and HR variability continuously on 10 cows during the sampling period using Polar HR monitors (RS800; Polar Electro Oy, Helsinki, Finland). A Polar HR strap was fastened firmly around the thorax, directly behind the shoulder, with the monitors attached. At each electrode contact point, ultrasound transmission gel (Aquasonic 100; Parker Laboratories Inc., Fairfield, NJ) was applied to the area, from which the hair had been removed. We used Polar software (Polar Precision Performance Software, version 4.03; Polar Electro Oy) to extract continuous recordings of $\mathrm{HR}$ and inter-beat interval $(\mathrm{R}-\mathrm{R}$ interval, the time interval between consecutive beats), and we calculated the root mean square of successive differences (RMSSD). Because inter-beat interval is prone to measurement errors (Marchant-Forde et al., 2004), we used the correction function in the Polar software to correct for artifacts. 
A

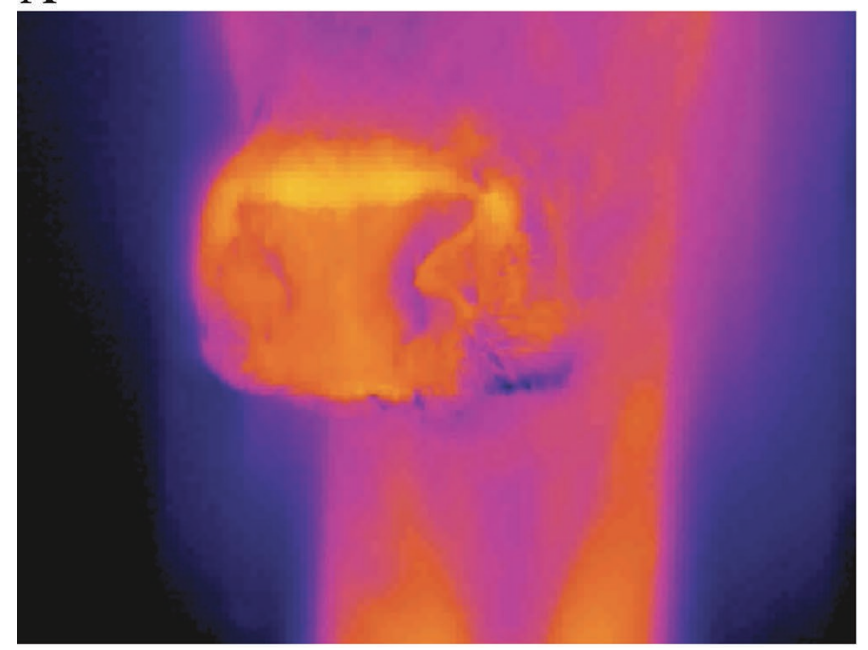

B

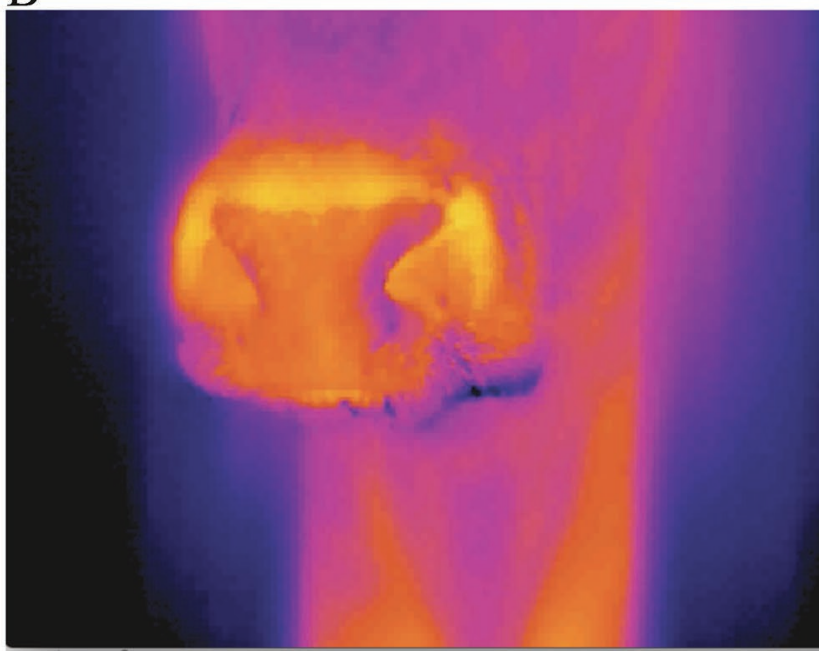

Figure 1. Infrared thermography images showing the cow (A) inhaling, and (B) exhaling.

\section{Flinch, Step, Kick Response}

On $\mathrm{d} 1$ and 2 , cows $(\mathrm{n}=22)$ were fitted with 2 Hobo Pendant G accelerometer data loggers (64k; Onset Computer Corp., Bourne, MA). The accelerometers were programmed to measure leg orientation via the $\mathrm{x}-, \mathrm{y}-$, and z-axes using the fast setting of $5 \mathrm{~Hz}$, which records every $0.2 \mathrm{~s}$. The accelerometers were placed in a durable fabric pouch and attached to the lateral side of both hind legs above the metatarsophalangeal joint. The pouch was held in place by a strap around the cow's leg. The data were downloaded using Onset HOBOware Pro software (version 3.4.1; Onset Computer Corp.).

We mounted a Sony HDR-CX220E digital HD video camera recorder (Sony, Shanghai, China) facing the right-hand side of the restraint at a height of approximately $2 \mathrm{~m}$, to continuously record all leg movements. One person observed the resulting video files and recorded the number of times each cow lifted her left or right hind leg. We scored the FSK response using definitions modified from Sutherland et al. (2012), which give a description of the height and direction of each leg movement (Table 1). We recorded the start and end time of each "cluster" of leg movements and compared this information with the downloaded data from the accelerometers.

\section{Statistical Analysis}

We tested the differences between pairs of methods for measuring RR using a mixed model with random animal effects, examined visually using Bland-Altman plots (differences plotted against averages). We assessed the change in HR, RR, and FSK after the startle using a repeated measures analysis and residual maximum likelihood in Genstat 18 (version 18, VSN International Ltd., Hemel Hempstead, UK). We examined the correlation between the number of movements seen on video with the number of high accelerations in the accelerometer data. We were not testing for equality for this relationship because, for example, an up-and-down leg movement would be expected to generate 2 high accelerations but be assessed as 1 movement. For a cow standing, the accelerometer should read $\mathrm{y}=-1.0$ for 1 $g$ gravity, and $\mathrm{x}=\mathrm{z}=0$. Therefore, we added 1 to the vertical (y) axis and calculated the overall acceleration as the square root of the sum of squares of the 3 axis values (after 1 had been added to the y-axis values). A visual inspection of the graphs of acceleration over time

Table 1. Description of flinch, step, kick (FSK) behaviors

\begin{tabular}{|c|c|}
\hline Score & Description \\
\hline 1 & The hoof slides forward or backward, or leg moves up or down or both, but without the hoof losing contact with the ground \\
\hline 2 & The hoof is lifted no higher than $20 \mathrm{~cm}$ off the ground \\
\hline 3 & The hoof is lifted higher than $20 \mathrm{~cm}$ off the ground \\
\hline 4 & Backward kick of hind leg \\
\hline
\end{tabular}


Table 2. Mean respiration rate $(\mathrm{RR})$ measured using 3 methods for cows $(\mathrm{n}=15)$ during the baseline period, while standing in the restraint, and following a startle

\begin{tabular}{lcccrrrr}
\hline & \multicolumn{3}{c}{ Mean RR (breaths/min) } & & & \\
\cline { 2 - 4 } Method & Baseline & Restraint & Startle & rdf $^{1}$ & SED $^{2}$ & P-value \\
\hline Live & 36.2 & 33.4 & 33.4 & 21.1 & 1.3 & 0.085 \\
Video & - & 37.2 & 35.8 & 9.0 & 1.6 & 0.412 \\
Infrared thermography & 44.6 & 39.0 & 39.2 & 16.7 & 2.8 & 0.118 \\
\hline
\end{tabular}

${ }^{1} \mathrm{rdf}=$ residual degrees of freedom

${ }^{2}$ Standard error of the difference.

showed that the values were almost constant (baseline values), apart from a small percentage that were clearly much larger and associated with leg movements. Baseline levels varied a little between animals (range 0.25 to $0.50 \mathrm{~g}$ ), with the 95 percentile varying from 0.32 to 0.73 . We found that taking any acceleration over 0.75 $g$ as a leg movement ensured that we were above the scatter of baseline levels and gave us a good correlation between the number of movements seen in the videos and the number of movements picked up by the accelerometers. We also analyzed how well the acceleration data correlated with the number of movements if data from only 1 or 2 of the axes were available.

\section{RESULTS}

\section{$R R$}

We observed no change $(P \geq 0.085)$ in $\mathrm{RR}$ in response to the startle using any of the methods (Table 2). The Bland-Altman plots indicated good agreement between the different methods of measuring RR. Overall, we observed little difference in $\mathrm{RR}$ between the pairs of methods (Figure 2). The average difference in $\mathrm{RR}$ was $-0.01 \pm 0.87,0.83 \pm 0.57$, and $0.37 \pm 1.02$ breaths/ min for video versus live, IRT versus live, and IRT versus video, respectively (means $\pm \mathrm{SE}$ ).

\section{$H R$ and $H R$ Variability}

Heart rate increased in response to the startle (average over 2 min: 60.7, 60.4, and $70.4 \pm 3.1$ beats/min for baseline, restraint, and startle, respectively, $P<0.001$ ), and returned to baseline levels within $40 \mathrm{~s}$. We observed no change in RMSSD in response to the startle (average 89.5, 75.8, and $79.1 \pm 16.1 \mathrm{~ms}$ for baseline, restraint, and startle, respectively, $P=0.631$ ).

\section{Flinch, Step, Kick Response}

We observed no change in the number of leg lifts in response to the startle (restraint $7.6 \pm 1.68$, startle
$9.2 \pm 1.68, P=0.503$ ) or in the FSK score (restraint $1.9 \pm 0.09$, startle: $2.0 \pm 0.09, P=0.712$ ). Overall, the behavioral response of cows to the restraint or the startle was low: no cows scored a 4, and only 4 cows scored a 3. Acceleration was highly positively correlated with FSK scores of $\leq 3$ (total FSK movements) and $\leq 2$ over the entire 4 min sampling period, and moderately correlated with FSK scores of 1 (Figure 3 ) using data collected from all 3 axes.

Correlations were also positively correlated with FSK scores of $1, \leq 2$, and $\leq 3$ over the entire 4 min sampling period when acceleration data were used from just 1 or 2 of the axes; the $\mathrm{x}$ - and $\mathrm{y}$-axes were the best if using only 2 , and $\mathrm{x}$ was the best if using only 1 .

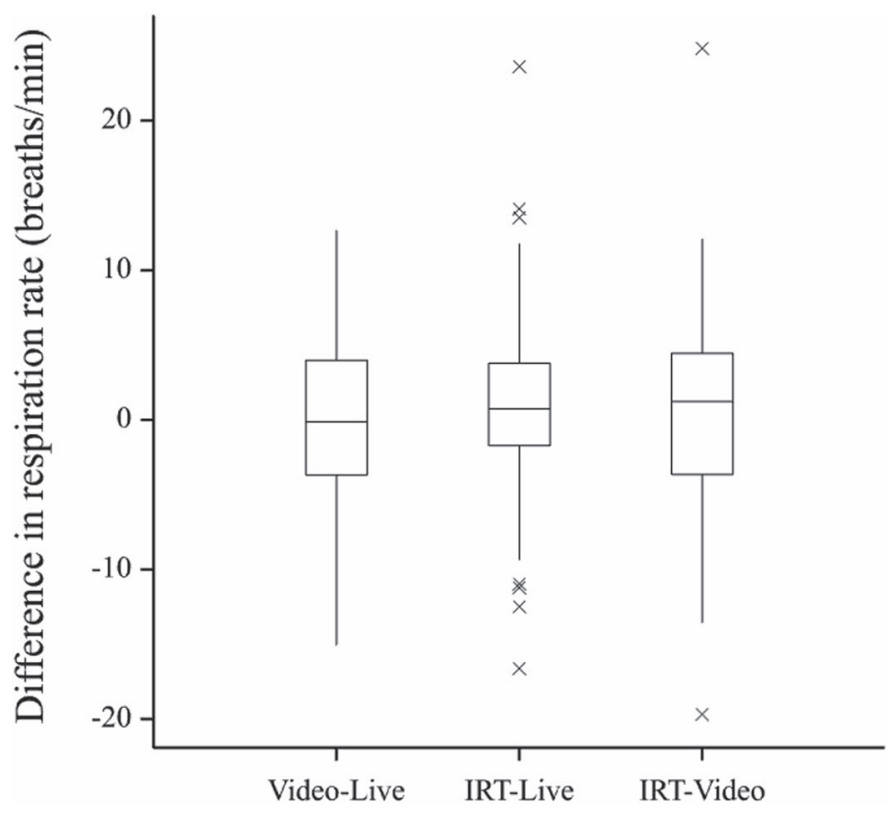

Figure 2. Difference in respiration rate (breaths/min) between pairs of the 3 methods: video versus live, infrared thermography (IRT) versus live, and IRT versus video. Box plots express median, 25 to $75 \%$ quartiles, minimum, maximum, and outliers. 
A

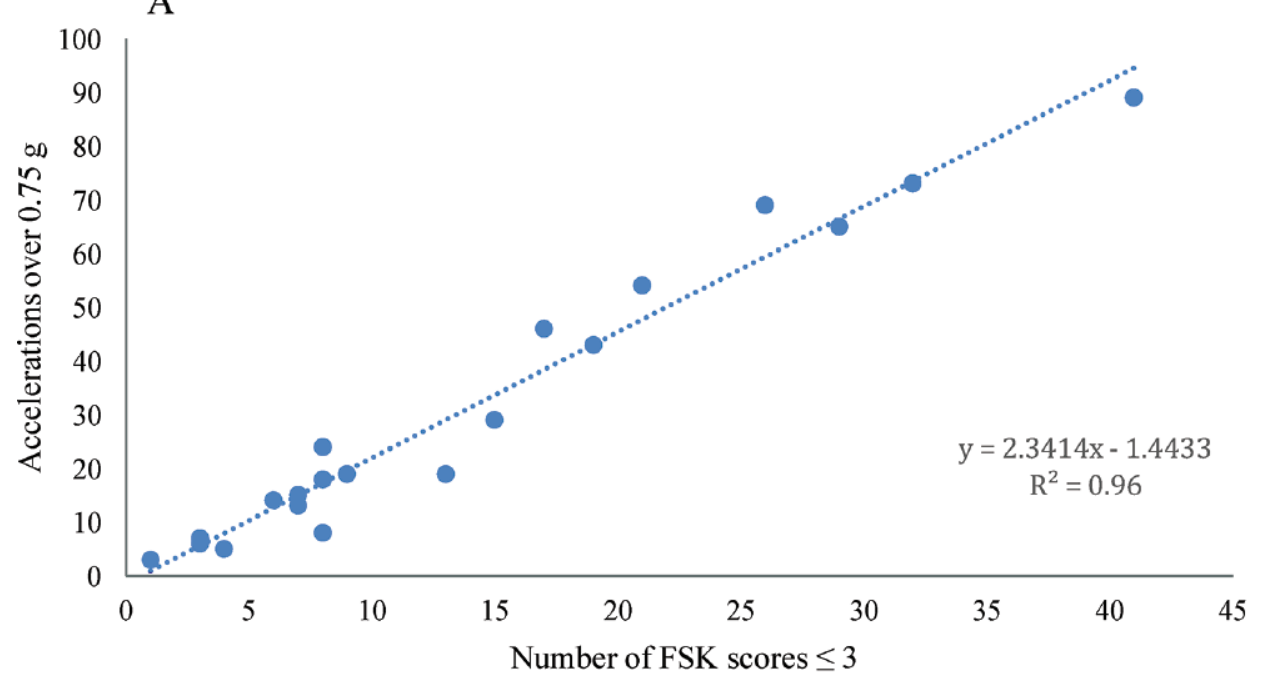

B

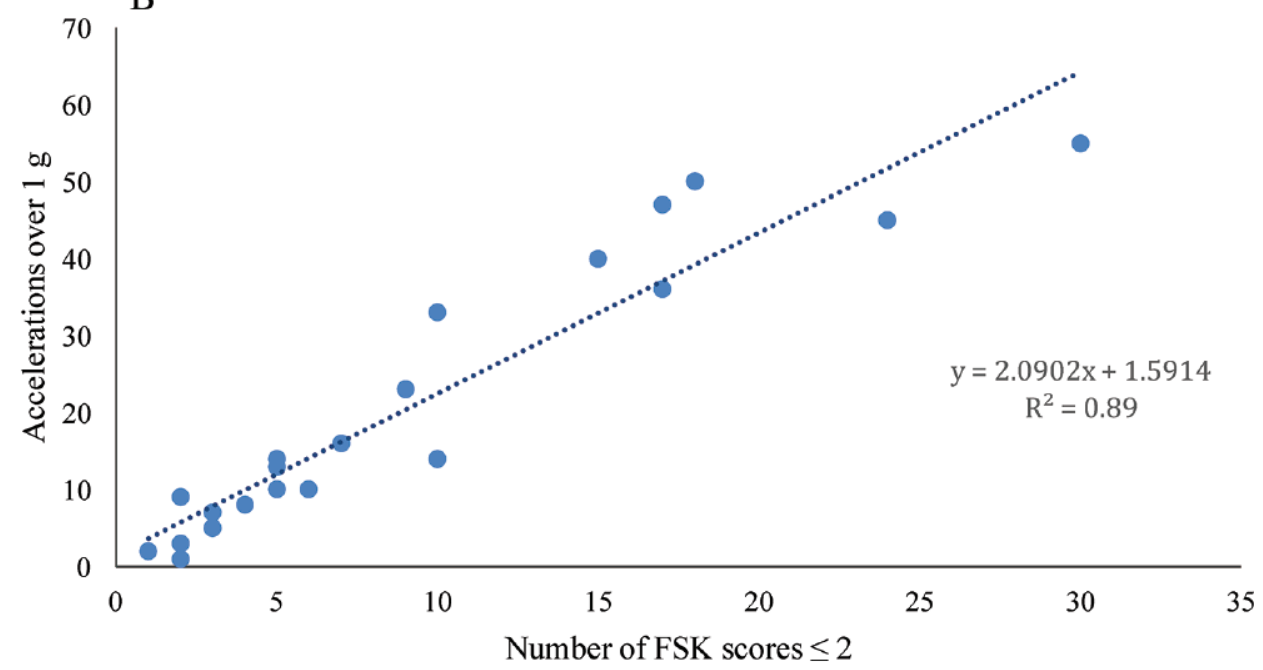

C

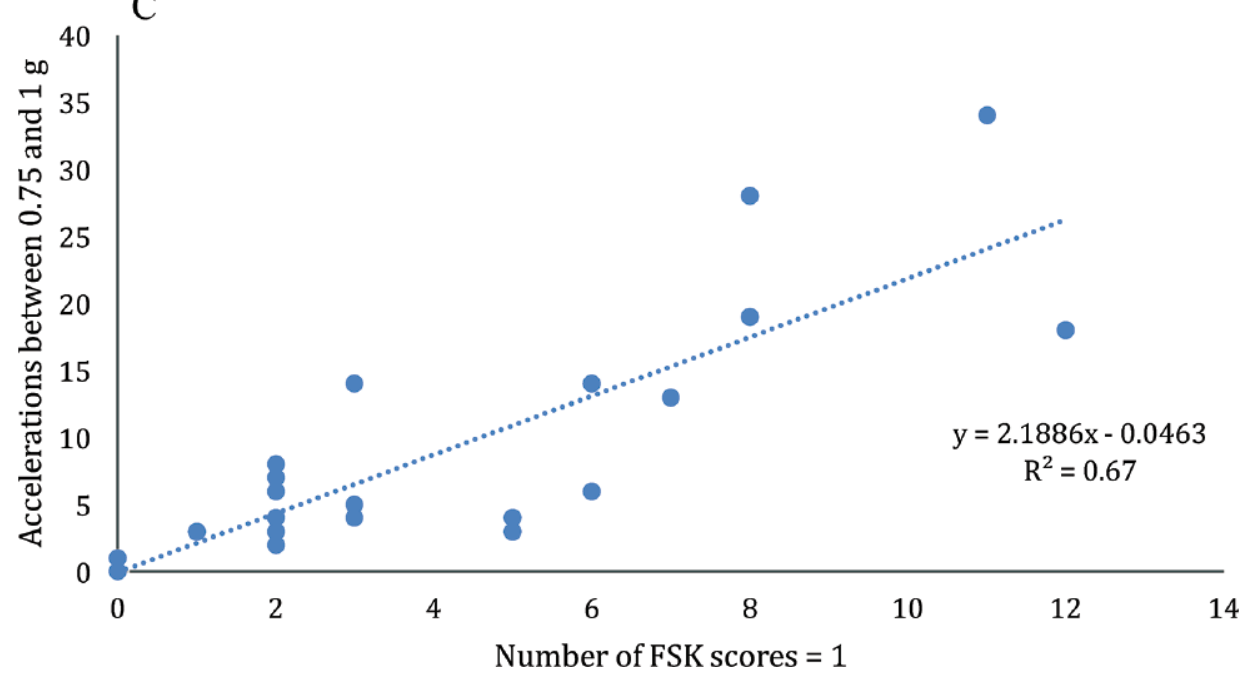

Figure 3. Correlation between flinch, step, kick (FSK) analyzed from video recordings and acceleration measured by accelerometers using data collected from all 3 axes over the 4-min sampling period while the cow was standing or restrained in a crush. Correlation between acceleration and number of FSK scores: $(\mathrm{A}) \leq 3,(\mathrm{~B}) \leq 2$, and $1(\mathrm{C})$. Color version available online. 


\section{DISCUSSION}

Remote, noninvasive monitoring of physiological and behavioral responses to stress, discomfort, and disease onset could provide valuable information about the health status of an animal. This study is the first demonstration that IRT can be used reliably to measure RR remotely in dairy cows and shows that this technology could be a noninvasive alternative to counting flank movements. In addition, FSK response can be measured remotely using accelerometers.

The lack of response to the startle as measured by RR, RMSSD (a measure of HR variability), and FSK, as well as the relatively brief effect on HR, suggests that the model used to simulate a startle or reaction was not effective in this study. Shouting has been shown to be aversive to cattle (Pajor et al., 2000) and has been used to simulate a fright response in cattle (Stewart et al., 2008). The lack of response in the cows used in the present study may have been because they had been extensively handled and were experienced with human contact. Responses to other types of stress, such as anxiety or pain, may be more apparent. Heart rate and HR variability have been used in recent studies investigating the autonomic nervous system response to various husbandry procedures in dairy cattle, and these studies (along with some of the benefits and limitations of measuring cardiac responses) have been thoroughly reviewed (von Borell et al., 2007; Kovács et al., 2014). One study in dairy calves reported significant HR increases in response to disbudding and ear tagging (by 18 and $10 \mathrm{bpm}$, respectively) and significant increases in RR (by 9 breaths/min) after disbudding but not after ear tagging (Stewart et al., 2013). In the present study, the changes in HR and the lack of response in RR were similar to calves' response to ear tagging. However, many factors need to be considered when comparing studies, including age, experience, and the level and nature of the stressor (e.g., pain, fear, disease).

Using IRT, it was easy to observe and count breaths by changes in temperature due to air movement through the nostrils, and IRT was highly correlated with the other methods (video footage and real-time counting of flank movements). Breaths could be automatically detected by an algorithm and used to measure RR in an automated system. We observed small differences in RR estimated from each method; this would be expected for counts based on physical flank movements vs. nostril air flow, given that the flank movements involve more movement of the diaphragm versus lung functionality, and each counting method could be influenced more or less by different factors (e.g., sighs, vocalizations, rumination). Counting flank movements has been validated as a reliable method of measuring RR (Schütz et al., 2014), but it is labor-intensive and can be prone to inaccuracies (e.g., because of shallow breathing). The use of IRT has advantages, including the noninvasive nature of the data collection, opportunities to automate recording using appropriate algorithms, and the possibility of measuring the depth of the breath as well as RR. Lewis et al. (2011) described a method of extracting respiratory parameters from IRT recordings across a range of breathing patterns in human subjects, including relative tidal volume and $R R$, using facial tracking algorithms. They found strong correlations between IRT and traditional devices that use strain gauges to measure RR using thoracic movements.

The ability to use IRT to measure relative tidal volume and extract this information automatically in dairy cows could be useful for early disease detection, when tidal volume can change (e.g., during the onset of metabolic or respiratory disease). This information could be combined with thermal changes on other body sites using an IRT system. For example, Schaefer et al. (2012) used an automated IRT system installed at a water trough and found eye temperature responses in bovine respiratory disease that occurred several days to a week before clinical signs were apparent. Furthermore, Martello et al. (2016) reported positive correlations between RR and IRT temperatures of different body areas, including the eye, cheek, and back in beef cattle. Combining automated IRT thermal and RR measures could strengthen a predictive index for early disease detection.

Environmental factors need to be considered when using IRT on-farm, such as sunlight, dust, and the distance between the camera and the animal, which can affect temperature outputs. Still, IRT lends itself to integration into other systems (e.g., automatic feeder or milking system, rotary platform, or drinking trough) because the camera can be positioned at a set distance from the animal. As well, because the animals visit daily, deviations from baseline levels can be determined using historic data. Furthermore, most of these systems have some degree of cover that would reduce solar loading, or cover could be provided.

In the present study, data collected from accelerometers were positively correlated with manually recorded FSK scores. In addition, it may be possible to detect different degrees of FSK responsiveness using accelerometers. Several studies have reported a possible relationship between cow restlessness in the milking parlor (flinch, step, or kick) and milk production (Willis, 1983; Breuer et al., 2000; Hedlund and Løvlie, 2015); this possible association may indicate a stressful situation. The FSK response in cows during 
milking has also been associated with udder health and clinical signs of mastitis (Rousing et al., 2004; Pastell et al., 2006; Medrano-Galarza et al., 2012; Fogsgaard et al., 2015), and with lameness (Pastell et al., 2006). In these studies, the FSK response was measured manually using live observations or videos, or using equipment such as strain gauge scales installed under the floor of an automatic milking machine, which measured the weight of each leg while cows were standing during milking (Pastell et al., 2006). Both of these methods for assessing FSK response are impractical in a large rotary or herringbone milking platform. The advantage of accelerometers is that they are already commonly used for other types of monitoring on-farm, such as estrus detection, and therefore would require no further investment in equipment or software for many farms. However, further investigations into cows' response to different health issues is still required, as well as optimizing the data collected and development of appropriate algorithms (i.e., specific to FSK).

\section{CONCLUSIONS}

In conclusion, our results show that accelerometers can provide an indirect measure of the FSK response, and IRT can be used reliably to measure RR. As a next step, we will further develop image-processing techniques to automate the extraction of $\mathrm{RR}$ from IRT images in real time so this information can be integrated into other automated systems on-farm. This information, combined with remote sensing of FSK, integrated into existing systems where other production and behavioral information is available (e.g., the number of visits, feed intake, milk yield) could provide noninvasive, real-time assessment of animal health and welfare. Combined with other thermal data using IRT, an automated system may be able to identify animals with early onset of pathological or metabolic diseases and distress or discomfort, allowing early intervention by the farmer and improving animal health, production, and welfare.

\section{ACKNOWLEDGMENTS}

The authors thank Gemma Lowe, Melissa Hempstead, Chloé Picchiottino, and Suzanne Dowling (AgResearch Ltd., Hamilton, New Zealand) for their technical assistance during this study, and Vanessa Cave (AgResearch Ltd.) and Neil Cox (NeilStat Ltd., Hamilton, New Zealand) for their assistance with the statistical analysis. This project was funded by the New Zealand Ministry of Business, Innovation and Employment, Wellington, and InterAg, Hamilton, New Zealand.

\section{REFERENCES}

Abbas, A. K., K. Heimann, K. Jergus, T. Orlikowsky, and S. Leonhardt. 2011. Neonatal non-contact respiratory monitoring based on real-time infrared thermography. Biomed. Eng. Online 10:93.

Alsaaod, M., and W. Büscher. 2012. Detection of hoof lesions using digital infrared thermography in dairy cows. J. Dairy Sci. 95:735742 .

Borchers, M. R., and J. M. Bewley. 2015. An assessment of producer precision dairy farming technology use, prepurchase considerations, and usefulness. J. Dairy Sci. 98:4198-4205.

Breuer, K., P. H. Hemsworth, J. L. Barnett, L. R. Matthews, and G. J. Coleman. 2000. Behavioural response to humans and the productivity of commercial dairy cows. Appl. Anim. Behav. Sci. $66: 273-288$.

DairyNZ. 2015. New Zealand Dairy Statistics 2014-2015. Accessed Jan. 10, 2017. https://www.dairynz.co.nz/media/3136117/newzealand-dairy-statistics-2014-15.pdf.

Eigenberg, R. R., G. L. Hahn, J. A. Nienaber, T. M. Brown-Brandl, and D. E. Spiers. 2000. Development of a new respiration rate monitor for cattle. Am. Soc. Agric. Eng. 43:723-728.

Fogsgaard, K. K., T. W. Bennedsgaard, and M. S. Herskin. 2015. Behavioral changes in freestall-housed dairy cows with naturally occurring clinical mastitis. J. Dairy Sci. 98:1730-1738.

Gershwin, L. J., A. L. Van Eenennaam, M. L. Anderson, H. A. McEligot, M. X. Shao, and R. Toaff-Rosenstein. 2015. Single pathogen challenge with agents of the bovine respiratory disease complex. PLoS One 10:e0142479. https://doi.org/10.1371/journal. pone.0142479.

Hedlund, L., and H. Løvlie. 2015. Personality and production: Nervous cows produce less milk. J. Dairy Sci. 98:5819-5828.

Kovács, L., V. Jurkovich, M. Bakony, O. Szenci, P. Póti, and J. Tőzsér. 2014. Welfare implication of measuring heart rate and heart rate variability in dairy cattle: Literature review and conclusions for future research. Animal 8:316-330.

Lewis, G. F., R. G. Gatto, and S. W. Porges. 2011. A novel method for extracting respiration rate and relative tidal volume from infrared thermography. Psychophysiology 48:877-887.

Lowe, G. L., A. L. Schaefer, J. R. Waas, M. T. Wilson, M. A. Sutherland, and M. Stewart. 2016. Brief communication: The use of infrared thermography and feeding behaviour for early disease detection in New Zealand dairy calves. Pages 177-179 in Proc. N.Z. Soc. Anim. Prod., Adelaide, Austrailia.

Lyons, N. A., C. R. Eastwood, B. T. Dela Rueb, and K. L. Kerrisk. 2016. Current and future adoption of milking related technologies on Australian and New Zealand dairy farms. Pages 445-450 in Proc. Int. Precision Dairy Farming Conf., Leeuwarden, the Netherlands.

Marchant-Forde, R. M., D. J. Marlin, and J. N. Marchant-Forde. 2004. Validation of a cardiac monitor for measuring heart rate variability in adult female pigs: Accuracy, artefacts and editing. Physiol. Behav. 80:449-458

Martello, L. S., S. da Luz E Silva, R. da Costa Gomes, R. R. da Silva Corte, and P. R. Leme. 2016. Infrared thermography as a tool to evaluate body surface temperature and its relationship with feed efficiency in Bos indicus cattle in tropical conditions. Int. J. Biometeorol. 60:173-181.

Medrano-Galarza, C., J. Gibbons, S. Wagner, A. M. de Passillé, and J. Rushen. 2012. Behavioral changes in dairy cows with mastitis. J. Dairy Sci. 95:6994-7002.

Pajor, E. A., J. Rushen, and A. M. B. de Passillé. 2000. Aversion learning techniques to evaluate dairy cattle handling practices. Appl. Anim. Behav. Sci. 69:89-102.

Pastell, M., A. M. Aisla, M. Hautala, V. Poikalainen, J. Praks, I Veermäe, and J. Ahokas. 2006. Contactless measurement of cow behavior in a milking robot. Behav. Res. Methods 38:479-486.

Polat, B., A. Colak, M. Cengiz, L. E. Yanmaz, H. Oral, A. Bastan, S. Kaya, and A. Hayirli. 2010. Sensitivity and specificity of infrared thermography in detection of subclinical mastitis in dairy cows. J. Dairy Sci. 93:3525-3532. 
Roelofs, J. B., and E. van Erp-van der Kooij. 2015. Estrus detection tools and their applicability in cattle: Recent and perspectival situation. Anim. Reprod. 12:498-504.

Rousing, T., M. Bonde, J. H. Badsberg, and J. T. Sørensen. 2004 Stepping and kicking behaviour during milking in relation to response in human-animal interaction test and clinical health in loose housed dairy cows. Livest. Prod. Sci. 88:1-8.

Schaefer, A. L., N. J. Cook, C. Bench, J. B. Chabot, J. Colyn, T. Liu, E. K. Okine, M. Stewart, and J. R. Webster. 2012. The noninvasive and automated detection of bovine respiratory disease onset in receiver calves using infrared thermography. Res. Vet. Sci. 93:928-935.

Schaefer, A. L., N. J. Cook, S. V. Tessaro, D. Deregt, G. Desroches, P. L. Dubeski, A. K. W. Tong, and D. L. Godson. 2004. Early detection and prediction of infection using infrared thermography. Can. J. Anim. Sci. 84:73-80.

Schütz, K. E., N. R. Cox, and C. B. Tucker. 2014. A field study of the behavioral and physiological effects of varying amounts of shade for lactating cows at pasture. J. Dairy Sci. 97:3599-3605.

Stewart, M., A. L. Schaefer, D. B. Haley, J. Colyn, N. J. Cook, K. J. Stafford, and J. R. Webster. 2008. Infrared thermography as a non-invasive method for detecting fear-related responses of cattle to handling procedures. Anim. Welf. 17:387-393.

Stewart, M., H. M. Shepherd, J. R. Webster, J. R. Waas, L. M. McLeay, and K. E. Schütz. 2013. Effect of previous handling ex- periences on responses of dairy calves to routine husbandry procedures. Animal 7:828-833.

Stewart, M., J. M. Stookey, K. J. Stafford, C. B. Tucker, A. R. Rogers, S. K. Dowling, G. A. Verkerk, A. L. Schaefer, and J. R. Webster. 2009. Effects of local anesthetic and a non-steroidal anti-inflammatory drug on pain responses of dairy calves to hot-iron dehorning. J. Dairy Sci. 92:1512-1519.

Sutherland, M. A., A. R. Rogers, and G. A. Verkerk. 2012. The effect of temperament and responsiveness towards humans on the behavior, physiology and milk production of multi-parous dairy cows in a familiar and novel milking environment. Physiol. Behav. 107:329-337.

Talukder, S., K. L. Kerrisk, L. Ingenhoff, P. C. Thomson, S. C. Garcia, and P. Celi. 2014. Infrared technology for estrus detection and as a predictor of time of ovulation in dairy cows in a pasture based system. Theriogenology 81:925-935.

von Borell, E., J. Langbein, G. Despres, S. Hansen, C. Leterrier, J Marchant-Forde, R. Marchant-Forde, M. Minero, E. Mohr, A. Prunier, D. Valance, and I. Veissier. 2007. Heart rate variability as a measure of autonomic regulation of cardiac activity for assessing stress and welfare in farm animals - A review. Physiol. Behav. 92:293-316.

Willis, G. L. 1983. A possible relationship between the flinch, step and kick response and milk yield in lactating cows. Appl. Anim. Ethol. 10:287-290. 